\title{
Pemberian Surat Persetujuan Berlayar (SPB) dalam Upaya Pemenuhan Keselamatan Berlayar
}

\author{
Sonhaji \\ Fakultas Hukum, Universitas Diponegoro \\ Sonhajimuh19@gmail.com
}

\begin{abstract}
Issuance of Port Clearance is about process controlled by Harbor Master for ships that will sailing to leaving harbor to confirm that ships, ship crews, and the cargo are technically administrative have fulfilled the safety requirements and shipping security as well as the protection of the maritime environment. As for the approach method used in this undergraduate thesis is empirical juridical and the research specifications used are descriptive analytical. Data aggregation techniques conducted in this study are through interview guidelines and documentation. The result of this research is Harbor Master's responsibility is very difficult to guarantee safety requirements and shipping security because Harbor Master is a government official at the port that has the highest authority to carry out and supervise toward the fulfillment regulations to guarantee the safety requirements and shipping security is about the condition fulfilled safety and security requirement relating to water transportations, ports, and maritime environment.
\end{abstract}

Keywords : Port Clearance, Sailing Safety, Law Number 17 of 2008 about Shipping

\begin{abstract}
Abstrak
Penerbitan Surat Persetujuan Berlayar merupakan suatu proses pengawasan yang dilakukan oleh Syahbandar terhadap kapal yang akan berlayar meninggalkan pelabuhan untuk memastikan bahwa kapal, awak kapal, dan muatannya secara teknis administratif telah memenuhi persyaratan keselamatan dan keamanan pelayaran serta perlindungan lingkungan maritim. Adapun metode pendekatan yang digunakan dalam penelitian ini adalah yuridis empiris dan spesifikasi penelitian yang digunakan adalah deskriptif analitis. Teknik pengumpulan data yang dilakukan dalam penelitian ini adalah melalui pedoman wawancara dan dokumentasi. Hasil penelitian ini yaitu tanggung jawab Syahbandar memang sangat berat dalam menjamin keselamatan dan keamanan pelayaran karena Syahbandar merupakan pejabat pemerintah di pelabuhan yang memiliki kewenangan tertinggi untuk menjalankan dan melakukan pengawasan terhadap dipenuhinya ketentuan peraturan perundang-undangan untuk menjamin keselamatan dan keamanan pelayaran. Pemahaman dari persyaratan keselamatan dan keamanan pelayaran adalah suatu keadaan terpenuhinya persyaratan keselamatan dan keamanan yang menyangkut angkutan diperairan, kepelabuhan, dan lingkungan maritime.
\end{abstract}

Kata kunci : Surat Persetujuan Berlayar, Keselamatan Berlayar, Anak Buah Kapal. 


\section{A. Pendahuluan}

Angkutan laut sebagai salah satu modal transportasi ditata dalam suatu kesatuan transportasi nasional yang terpadu dalam mewujudkan penyediaan jasa transportasi yang sesuai dengan kebutuhan dan tersedianya pelayanan angkutan yang aman, nyaman, tertib, dan efisien. Dalam usaha untuk mewujudhkan hal tersebut tentunya pemerintah mempunyai peran penting untuk menunjang kelancaran pelayaran yaitu dengan melakukan penegakan hukum di laut.

Salah satu upaya dalam penegakkan hukum di laut adalah pengawasan terhadap kapal-kapal yang berlayar di wilayah perairan di Indonesia. Kapal yang memenuhi syarat-syarat laik laut yang dapat berlayar di wilayah laut di Indonesia. Dalam pasal 1 angka 33 Undang-Undang Nomor 17 Tahun 2008 Tentang Pelayaran, Kelaiklautan Kapal adalah keadaan kapal yang memenuhi persyaratan keselamatan kapal, pencegahan pencemaran perairan dari kapal, pengawakan, garis muat, pemuatan, kesejahteraan awak kapal dan kesehatan penumpang, status hukum kapal, manajemen keselamatan dan pencegahan pencemaran dari kapal, dan manajemen keamanan kapal untuk berlayar di perairan tertentu.

Pentingnya Surat Persetujuan Berlayar secara khusus diatur dalam UndangUndang Nomor 17 Tahun 2008 Tentang Pelayaran. Sekalipun telah ada peraturan yang mengatur tentang Surat Persetujuan Berlayar, tidak jarang juga dapat ditemui beberapa kecelakaan transportasi laut yang disebabkan oleh lalainya pemberian ijin pelayaran. Masalah keselamatan dan keamanan serta keseluruhan kegiatan dalam pelayaran merupakan tanggungjawab dalam kepelabuhan. Salah satu persoalan terbesar dalam kecelakaan kapal dalam pelayaran adalah persoalan kemampuan dan keahlian seseorang dalam menjalankan tugas kesyahbandarannya dalam memberikan surat kelaiklautan kapal, ijin berlayar, keselamatan dan keamanan pelayaran, serta seluruh kegiatan pelayaran angkutan laut di perairan Indonesia. 


\section{Metode}

Metode pendekatam yang dipergunakan dalam penelitian ini adalah pendekatan yuridis empiris yaitu suatu prosedur yang dipergunakan untuk memecahkan masalah penelitian dengan meneliti data sekunder terlebih dahulu untuk kemudian dilanjutkan dengan mengadakan penelitian terhadap data primer di lapangan ${ }^{1}$. Data sekunder diperoleh dengan cara mempelajari dan mengkaji bahan-bahan kepustakaan yang berupa bahan hukum baik bahan hukum primer, bahan hukum sekunder, maupun bahan hukum tersier. Data primer yaitu data langsung yang diperoleh dari sumber data di lapangan dan diperoleh dengan menggunakan observasi dan wawancara.

Spesifikasi penelitian yang digunakan dalam penelitian ini adalah deskriptif analitis. Metode deskriptif yaitu pemecahan masalah dengan melukiskan atau memberi gambaran mengenai segala sesuatu yang berhubungan dengan obyek penelitian berdasarkan kenyataan yang ada. Sedangkan secara analisis yaitu mengandung makna mengelompokkan, menghubungkan, membandingkan dan memberi makna dikaitkan dengan teori-teori hukum yang ada yang berkaitan dengan obyek yang akan diteliti.

Analisa data yang digunakan dalam penelitian ini adalah analisa data secara kualitatif, yaitu proses pengumpulan data yang diperoleh dari hasil penelitian dianalisis tanpa menggunakan rumus statistik akan tetapi disajikan dalam bentuk konsep dan uraian sehingga pada akhirnya dapat ditarik menjadi suatu kesimpulan.

\section{B. Hasil Dan Pembahasan}

\section{Peran Syahbandar dalam penerbitan Surat Persetujuan Berlayar}

Setiap kapal yang akan berlayar wajib memiliki Surat Persetujuan Berlayar yang diterbitkan oleh Syahbandar. Untuk mendapatkan Surat Persetujuan Berlayar harus memenuhi syarat adminstratif dan syarat teknis. Pejabat kesyahbandaran melakukan verifikasi/pemeriksaan sertifikat dan dokumen kapal sebelum Surat

\footnotetext{
${ }^{1}$ Soerjono Soekanto, Pengantar Penelitian Hukum, (Jakarta: UI Press, 1986), hlm 45.
} 
Persetujuan Berlayar dan melakukan verifikasi/pemeriksaan visi kapal yang dinyatakan dengan layak untuk berlayar ${ }^{2}$. Untuk mendapatkan Surat Persetujuan Berlayar, Nahkoda/pemilik kapal harus mengajukan permohonan kepada Syahbandar dengan melampirkan dokumen kelaiklautan kapal. Syahbandar dapat menunda keberangkatan kapal setelah Surat Persetujuan Berlayar diterbitkan apabila persyaratan kelaiklautan, keamanan kapal dan kondisi cuaca dapat membahayakan keselamatan. Apabila penundaan keberangkatan kapal melebihi 24 (dua puluh empat) jam dari waktu tolak yang telah ditetapkan, maka Nahkoda/pemilik kapal wajib mengajukan surat permohonan ulang penerbitan SPB kepada Syahbandar dengan melampirkan alasan penundaan keberangkatan ${ }^{3}$. Selain adanya penundaan SPB, terdapat pula pembebasan Surat Persetujuan Berlayar yang mana hanya dapat diberikan oleh Syahbandar terhadap kapal yang berlayar dalam batas pelabuhan, kapal yang melakukan percobaan berlayar, kapal yang bertujuan memberikan bantuan pertolongan dan kapal yang menyinggahi pelabuhan karena keadaan darurat. Selain dapat melakukan pembebasan SPB, Syahbandar juga dapat mencabut SPB yang telah diterbitkan apabila kapal tidak berlayar meninggalkan pelabuhan melebihi 24 (dua puluh empat) jam dari batas waktu tolak yang ditetapkan, kapal mengganggu kelancaran lalu lintas kapal, dan adanya perintah tertulis dari Pengadilan Negeri.

\section{Pengaruh Pemberian Surat Persetujuan Berlayar Terhadap Aspek}

\section{Pemenuhan Keselamatan Berlayar}

Keselamatan dan keamanan pelayaran berdasarkan Pasal 116 UndangUndang Nomor 17 Tahun 2008 Tentang Pelayaran meliputi keselamatan dan keamanan angkutan di perairan, pelabuhan, serta perlindungan hukum maritime. Keselamatan dan keamanan angkutan perairan apabila memenuhi syarat kelaiklautan kapal dan kenavigasian. Kelaiklautan kapal wajib dipenuhi oleh setiap kapal yang meliputi:

\footnotetext{
${ }^{2}$ Heman Budi Sarsono, Manajemen Pelabuhan dan Realisasi Ekspor Impor, (Yogyakarta: Andi, 2012), hlm 42.

${ }^{3}$ Boy Prasojo, Wawancara, Syahbandar Pelabuhan Sapudi, (Pelabuhan Sapudi: Rabu, 8 Agustus, 2018)
} 

a. Keselamatan kapal;
b. Pencegahan pencemaran kapal;
c. Pengawakan kapal;
d. Garis muat kapal dan pemuatan;
e. Kesejahteraan awak kapal dan kesehatan penumpang;
f. Status hukum kapal;
g. Manajemen keselamatan dan pencegahan pencemaran dari kapal; dan
h. Manajemen keamanan kapal.

Sedangkan kenavigasian terdiri dari:
a. Sarana Bantu Navigasi-Pelayaran;
b. Telekomunikasi-Pelayaran;
c. Hidrografi dan meteorologi;
d. Alur dan perlintasan;
e. Pengerukan dan reklamasi;
f. Pemanduan;
g. Penanganan kerangka kapal; dan
h. Salvage dan pekerjaan bawah air.

Berdasarkan pasal 1 angka 34 Undang-Undang Nomor 17 Tahun 2008 Tentang Pelayaran, keselamatan kapal dapat dibuktikan dengan sertifikat setelah dilakukan pemeriksaan dan pengujian. Sertifikat keselamatan diberikan kepada semua jenis kapal yang berukuran lebih dari 7 GT, kecuali untuk kapal perang dan kapal negara.

Sesuai dengan Peraturan Pemerintah Nomor 51 Tahun 2002 Tentang Perkapalan, kapal yang telah memperoleh sertifikat, dilakukan pengecekan secara terus-menerus sampai kapal tidak digunakan lagi artinya sertifikat-sertifikat kapal tersebut tidak berlaku bilamana masa berlaku sertifikat telah berakhir. Sertifikat kapal juga dapat dibatalkan apabila keterangan dalam dokumen kapal yang digunakan untuk penerbitan sertifikat ternyata tidak sesuai dengan keadaan sebenarnya atau kapal sudah tidak memenuhi persyaratan keselamatan kapal, atau 
sertifikat diperoleh secara tidak sah. Berdasarkan Undang-Undang Nomor 17 Tahun 2008 Tentang Pelayaran, sertifikat ini berupa sertifikat keselamatan kapal penumpang dan sertifikat keselamatan kapal barang.

\section{Kesimpulan}

Syahbandar berperan penting dalam sistem kepelabuhan baik dalam pelayaran, penegakan hukum, maupun mengkoordinasi kegiatan yang berlangsung dalam pelabuhan. Tanggungjawab Syahbandar sangatlah penting karena keamanan dan keselamatan berlayar sudah menjadi tugas Syahbandar. Tindakan yang dilakukan Syahbandar adalah/agar untuk meningkatkan pengawasan keamanan dan keselamatan terhadap hal-hal yang berhubungan dengan pelayaran. Penerbitan Surat Persetujuan Berlayar merupakan suatu proses pengawasan yang dilakukan oleh Syahbandar terhadap kapal yang akan berlayar meninggalkan pelabuhan untuk memastikan bahwa kapal, awak kapal, dan muatannya secara teknis-administratif telah memenuhi persyaratan keselamatan dan keamanan pelayaran. Diperolehnya Surat Persetujuan Berlayar otomatis syarat-syarat yang harus dipenuhi untuk memperoleh izin tersebut telah memenuhi syarat yang ditentukan oleh peraturan perundang-undangan sehingga ada hubungan antara Surat Persetujuan Berlayar dengan upaya keselamatan berlayar.

\section{Daftar Pustaka}

Eko Putri, Normalita. 2016. Pelaksanaan Tugas dan Wewenang Syahbandar Dalam Penerbitan Surat Persetujuan Berlayar Kapal Perikanan. Diponegoro Law Journal, Volume 5, Angka 3.

Ludiro Madu, A.N. 2010. Mengelola Perbatasan Indonesia di Dunia Tanpa Batas, Isu, Permasalahan dan Pilahan Kebijakan. Yogyakarta: Graha Ilmu.

Meleong, Lexy J. 2006. Metode Penelitian Kualitatif. Bandung: Remaja Rosda Karya.

Nazir, Mohammad. 2003. Metode Penelitian. PT. Ghalia Indonesia: Jakarta.

Njatrijani, Rinitami. 2015. Hukum Transportasi. UNDIP LAW PRESS FAKULTAS HUKUM UNIVERSITAS DIPONEGORO: Semarang.

Santoso, Djohari. 2004. Pokok-Pokok Hukum Perkapalan. Yogyakarta: UII Press. 
Sarsono, Herman Budi. Manajemen Pelabuhan dan Realisasi Ekspor Impor. Andi: Yogyakarta.

Simangunsong, Bonar. 2015. Laut, Masa Depan Indonesia. Jakarta: Gematama.

Soekanto, Soerjono. 1986. Pengantar Penelitian Hukum. Jakarta: UII Press.

Soemitro, Ronny Hanitijo. 1990. Metodologi Penelitian Hukum. Jakarta: Ghalia Indonesia.

Soerjono Soekanto dan Sri Mamudji. 1990. Penelitian Hukum Normatif "Suatu Tinjauan Singkat”. Rajawali Press: Jakarta.

Subagyo, P. 2006. Metode Penelitian. PT. Rineka Cipta: Jakarta.

Sukardi. 2003. Metodologi Penelitian Pendidikan Kompetensi dan Praktiknya. Jakarta: Bumi Aksara.

Supit, Capt. Hengky. 2009. Pedoman Khusus Keselamatan dan Keamanan Pelayaran. BARORKAMLA: Jakarta.

Suyono, R.P. 2007. Shipping: Pengangkutan Intermoda Ekspor Impor Melalui Laut. PPM Manajemen: Jakarta.

Syamsudin, M. 2007. Operasionalisasi Penelitian Hukum. Jakarta: Raja Grafindo Persada.

Triatmodjo, Bambang. 2009. Perencanaan Pelabuhan. Yogyakarta: Beta Offset Yogyakarta.

Utari, Siti. 1994. Pengangkutan Laut Di Indonesia (Suatu Tinjauan Yuridis). Jakarta: Balai Pustaka.

Waluyo, Bambang. 2002. Penelitian Hukum Dalam Praktek. Jakarta: Sinar Grafika.

Yanto, Nur. 2014. Memahami Hukum Laut Indonesia. Jakarta: Mitra Wacana Media. 